\title{
Perspectivas para o controle do carrapato bovino
}

\author{
Perspectives for control of bovine tick \\ Alexandre Trindade Leal ${ }^{1}$, Daniela Reis J oaquim de Freitas ${ }^{1} \&$ Itabajara da Silva Vaz J r ${ }^{1,2}$
}

\begin{abstract}
RESUMO
O carrapato Boophilus microplus é um ectoparasita de bovinos, presente em áreas tropicais e subtropicais na América, África, Ásia e Austrália. O método atual para o controle do carrapato bovino Boophilus microplus é o uso de acaricidas. Porém, este método é caro devido aos custos das drogas e aos da mão de obra exigida para a sua aplicação. Também, existem relatos de carrapatos resistentes a diversos acaricidas. Além disso, os resíduos químicos na alimentação e a poluição ambiental são uma grande preocupação a ser considerada. Para superar estes problemas, métodos alternativos não-químicos incluem o uso de animais geneticamente resistentes, o desenvolvimento de vacinas, o gerenciamento de pastagem com alternância de espécies e o controle biológico. Neste momento, a proteção induzida por vacinas não é suficiente para permitir o controle do B. microplus. Entretanto, os resultados sugerem ser possível o uso combinado destes métodos para o controle do carrapato a fim de reduzir o uso de acaricidas químicos.
\end{abstract}

Descritores: Boophilus microplus, vacina, controle, acaricida.

\begin{abstract}
The tick Boophilus microplus is an ectoparasite of bovine, present in tropical and subtropical areas, as America, Asia, Africa and Australia. The current method for the control of the cattle tick B. microplus is the use of chemicals. However, this method is expensive due to the costs of both drugs and to the labor required to apply treatment. Moreover, there are observations of tick isolates resistant to the acaricides. In addition, chemical residues in food and environmental pollution are a major concern nowadays. To overcome these problems alternative non-chemical methods to control the cattle tick are under development. The non-chemical methods include the use of genetically resistant cattle, the development of vaccines, pasture management, alternate grazing of different species of hosts and biological control. In this moment, the protection induced by vaccination is not enough to permit the control of the B. microplus. However, the results suggest that it is possible to envisage the combined use of these methods for the control of cattle tick in order to reduce the use of chemical acaricides.
\end{abstract}

Key words: Boophilus microplus, vaccine, control, acaricide.

* Este trabalho recebeu apoio financeiro do PADCT, PRONEX, FAPERGS and CNPq. ${ }^{1}$ Centro de Biotecnologia do Estado do Rio Grande do Sul - UFRGS. ${ }^{2}$ Departamento de Patologia Clínica Veterinária, FAVET/UFRGS. CORRESPONDÊNCIA: Itabajara da Silva Vaz Junior [e-mail: ita@dna.cbiot.ufrgs.br] Centro de Biotecnologia do Estado do Rio Grande do Sul UFRGS. CP. 15005; 91501-970 Porto Alegre, RS - Brasil. 


\section{Introdução}

O carrapato Boophilus microplus é um ectoparasita hematófago originário da Ásia, cujo principal hospedeiro é o bovino. Encontra-se amplamente distribuído nos grandes rebanhos bovinos da América, África, Ásia e Oceania entre os paralelos $32^{\circ} \mathrm{Ne} 32^{\circ} \mathrm{S}$ [36], sendo um dos principais parasitos que afetam a pecuária destas áreas.

O B. microplus acarreta diversos danos econômicos [34], tornando-se o principal alvo de programas de controle e erradicação nos rebanhos da América do Sul [52], pois um carrapato bovino suga, em média, de $2 \mathrm{a} 3 \mathrm{~mL}$ de sangue do seu hospedeiro [26], o que se reflete em grandes perdas na produção de leite e carne [71] e danos no couro causados por reações inflamatórias nos locais de fixação do carrapato [67]. Também, o carrapato pode atuar como vetor de doenças, como a tristeza parasitária bovina, causada por protozoários do gênero Babesia e pela rickétsia do gênero Anaplasma [49,78]. Além disso, existem diversos prejuízos relacionados à mão-de-obra necessária para o controle desse parasita, despesas com instalações, compra de equipamentos adequados para aplicação de carrapaticida nos rebanhos e aquisição de carrapaticidas [9]. Estudos recentes na Austrália, calculam uma perda anual de 4 milhões de dólares na criação de gado, $49 \%$ desta perda devido aos custos do controle do carrapato e $51 \%$ devido a perdas na produção de leite, carne e couro [37].

\section{Métodos de controle}

O método de controle para o carrapato que mais tem sido utilizado desde a década de 50 é o uso de acaricidas [56]. Apesar de atualmente ser o único método eficaz é também dispendioso, além de poder causar danos ao meio ambiente e à saúde pública, através da contaminação de rios e solos. Ao longo destas décadas, foram utilizados, sequiencialmente, acaricidas baseados em compostos arsenicais, organoclorados, organofosforados, carbamato, formamidinas e piretróides. A troca dos princípios ativos tem sido uma necessidade devido ao surgimento de populações resistentes. Os três mais recentes grupos químicos de produtos contra o carrapato que se encontram disponíveis hoje no mercado são: as formamidinas, os piretróides e as avermectinas [29]. Diversos autores têm demonstrado a crescente resistência apresentada por carrapatos a compostos químicos presentes nos carrapaticidas [12]. A resistência para organofosforados tem sido reportada desde 1963, quando foi des- crito, na Austrália, um caso de resistência para dioxation, carbophenothion, diazinon e carbamyl, [66]. O B. microplus pode apresentar resistência mais rapidamente que outros carrapatos, presumivelmente, pelo menor período de tempo entre as gerações [40], o que demonstra a necessidade de desenvolver novas formas de controle desta espécie.

Portanto, devido aos problemas de resistência, ao alto custo dos produtos químicos e da mão-deobra na aplicação dos produtos, bem como o aparecimento de resíduos tóxicos na carne e no leite e a contaminação do ambiente, têm-se procurado novos métodos como formas alternativas de controle do carrapato $[53,56]$. Atualmente, os controles biológico e imunológico já constituem parte de programas de controle integrado de ectoparasitas, que ainda exigem a utilização de produtos químicos para maior estabilidade operacional [56].

\section{Controle biológico}

Os controles biológicos incluem a seleção de raças menos sensíveis ao carrapato; cultivo de pastagens que dificultam a sobrevivência das fases de vida livre [21, 70]; ação de predadores naturais, como a garça vaqueira Egretta ibis [1] e formigas [26].

Espécies parasitas também podem contribuir para a manutenção de baixos níveis populacionais de carrapato. Bactérias, como Escherichia coli, Cedecea lapagei e Enterobacter agglomerans são naturalmente encontradas no aparelho reprodutor feminino do carrapato. Existem relatos de uma diminuição de até $47 \%$ na quantidade de ovos postos quando fêmeas ingurgitadas de B. microplus eram imersas em suspensão de $C$. lapagei [6]. A utilização de fungos no controle do carrapato tem sido muito estudada nos últimos anos, como o fungo entomopatogênico Metarhizium anisopliae, altamente patogênico para o carrapato Ixodes scapularis [79]. Demonstrou-se que os fungos Beauveria bassiana e M. anisopliae induzem uma taxa de mortalidade de aproximadamente $30 \%$ em Rhipicephalus appendiculatus adultos alimentados em coelhos, enquanto que $M$. anisopliae induzem uma mortalidade de 37\% em Amblyomma variegatum adultos. E estes fungos não perdem sua capacidade de infecção sobre o carrapato quando são incubados com acaricida por mais de 5 dias, mantendo o crescimento e suas características morfológicas normais [38]. Experimentos in vitro com 12 isolados de M. anisopliae sobre 
fêmeas ingurgitadas de $B$. microplus mostram que, dependendo da concentração de esporos na suspensão utilizada, alguns isolados de $M$. anisopliae podem causar morte de até $100 \%$ dos carrapatos infectados [24]. Já foram identificados isolados de $M$. anisopliae ocorrentes no Brasil infestantes naturais de B. microplus [14]. Outros organismos parasitas, tais como nematódeos, tem sido também avaliados como ferramentas no controle biológico de carrapatos, já que têm se mostrado eficientes no controle de insetos [63].

Uma outra estratégia envolvendo controle biológico do carrapato é a utilização de compostos naturais como pesticidas. Davey et al. [18] testaram em bovinos diferentes concentrações de "spinosad", um acaricida natural de Sacharopolyspora spinosa (actinomiceto), advindo da mistura de dois metabólitos deste organismo, espinosina A e D, obtidos sob condições de fermentação. Os resultados mostram uma queda drástica no número de fêmeas ingurgitadas, na massa de ovos e no índice de fecundidade. Guglielmone et al. [28] mostraram que bovinos banhados em moxidectina, um composto endectocida que também atua como anti-helmíntico, tinham um controle de quase 95\% na infestação de carrapatos.

\section{Controle imunológico}

O controle de ectoparasitas através de vacinação tem sido estudado nas últimas cinco décadas. Aliado a isso, o rápido desenvolvimento da biotecnologia tem alavancado o desenvolvimento de novas vacinas. Para o desenvolvimento de uma vacina é necessário, além da identificação de proteínas capazes de induzir uma resposta imune protetora, o conhecimento dos mecanismos de resposta imunológica do animal. Bovinos infestados naturalmente com carrapatos desenvolvem linfócitos $\mathrm{T}$ e $\mathrm{B}$ de memória, que permitem uma resposta mais eficiente em futuras infestações [76]. A importância dos linfócitos T na indução e manutenção de uma resposta eficaz foi bem definida, apesar de não estar totalmente esclarecida a importância de cada tipo de resposta (celular ou humoral) para a proteção contra o carrapato.

A teoria dos "antígenos ocultos", aqueles não expostos ao sistema imune do hospedeiro durante uma infestação natural e, o achado de uma proteína de intestino (Bm86) com essa característica significaram um grande avanço no desenvolvimento de vacinas contra B. microplus. A Bm86 induz resposta imunológica em bovinos imunizados e é a base de duas vacinas comerciais presentes no mercado: a TickGard, desenvolvida na Austrália pela Divisão de Ciências Animais Tropicais do CSIRO, e a Gavac, desenvolvida no Centro de Engenharia Genética e Biotecnologia de Cuba. As duas vacinas são produzidas em sistema heterólogo, porém, a proteína da TickGard é obtida em E. coli e a da Gavac em Pichia pastoris. Embora essas vacinas estejam comercialmente disponíveis, elas não asseguram o grau de proteção necessário para suprimir o uso de acaricidas $[37,77]$. O grupo australiano descreveu e a avaliou um segundo antígeno oculto, denominado Bm91, que foi associado a Bm86 e aumentou a eficácia parcial da vacinação [60, 77].

Embora os antígenos ocultos sejam a base das vacinas comerciais e tenham sido estudados em outros ectoparasitas, como Lucilia cuprina e Pediculus humanus [75], experimentos com antígenos naturalmente expostos ao sistema imunológico do hospedeiro associado a antígenos ocultos, demonstram o potencial da associação de diferentes alvos em uma mesma vacina [75].

\section{A busca de novos antígenos}

Portanto, a identificação de novas moléculas e suas funções bioquímicas representam um campo fértil para o conhecimento dos mecanismos de interação parasita-hospedeiro e para obtenção de novos antígenos com potencial protetor. Além dos antígenos que compõem as vacinas comercialmente disponíveis descritas acima, outras proteínas que também conferem algum grau de imunoproteção ou induzem a produção de anticorpos que interferem no sucesso reprodutivo do carrapato tem sido descritas.

Uma glicolipoproteína de massa molecular 50.000, chamada de BYC (Boophilus Yolk Catepsina), foi detectada em ovos embrionários de B. microplus, onde parece atuar sobre a degradação da vitelina, a principal proteína de reserva dos ovos do carrapato [46]. A BYC é sintetizada no corpo gorduroso, secretada para a hemolinfa e captada pelo ovócito em crescimento e representa entre 5-8 \% das proteínas do ovo, sendo ativada por proteólise limitada durante a embriogênese [46]. Bovinos imunizados com BYC produziram imunoglobulinas que apareceram circulantes na hemolinfa de carrapatos que parasitaram estes animais. As imunoglobulinas circulantes na hemolinfa mantiveram sua atividade biológica, medida pela capacidade de ligação ao antígeno correspondente, 
o que indicou que os anticorpos podem atravessar o epitélio intestinal, e possivelmente reagir com antígenos localizados nos tecidos do meio interno do carrapato [16]. Esses dados foram reforçados pela inoculação de teleóginas com anticorpos monoclonais anti-BYC [BrBm5], que reduziram a taxa de sobrevivência entre $5,4 \%$ e $60 \%$ e o peso de ovos entre $2,5 \%$ e $52 \%$, respectivamente, para dose de $10 \mu \mathrm{g}$ e $50 \mu \mathrm{g}$, demonstrando que os efeitos foram dependentes da concentração de anticorpos inoculados [17]. Quando bovinos imunizados com BYC foram desafiados com larvas infestantes houve redução no número de teleóginas, capacidade de postura e na fertilidade dos ovos, com eficácia variando entre $14 \%$ e $36 \%$ em dois experimentos independentes. Os níveis de anticorpos declinaram gradualmente após a infestação e responderam positivamente a um reforço vacinal, aplicado 11 meses após a infestação, indicando a existência de memória imunológica para esse antígeno [17].

Inibidores de tripsina (BmTIs) foram detectados em concentrações variáveis nas diferentes fases de desenvolvimento do B. microplus, indicando um possível papel na interação parasita-hospedeiro. Esses BmTIs, purificados de larvas, tiveram sua atividade inibidora para tripsina comprovada através de zimograma reverso e foram usados como antígeno para imunização de bovinos [2]. Bovinos foram imunizados com BmTIs e após desafiados com larvas de B. microplus. Os níveis de IgG anti BmTIs, monitorados por ELISA, tiveram seu pico 40 dias após a primeira imunização (título 8.000) e apresentaram diminuição após a infestação, atingindo $50 \%$ do título máximo 3 meses após o desafio. A ausência de anticorpos anti-BmTIs nos bovinos usados como controle sugere que esse antígeno não é reconhecido na infestação natural. Os bovinos imunizados apresentaram redução de $67,9 \%$ no número total de carrapatos, $71,3 \%$ no peso total de ovos e $69,5 \%$ no peso total das fêmeas ingurgitadas, quando comparados aos bovinos controles. Os demais parâmetros (peso dos ovos/número de carrapatos, peso das fêmeas ingurgitadas/ animal, peso dos ovos/peso das fêmeas ingurgitadas) não tiveram diferenças significativas em relação ao grupo controle. A eficácia final da vacinação com BmTIs foi de 72,8\% [2].

Visando melhorar os resultados obtidos com a proteína $\mathrm{Bm} 86$, foram desenvolvidos 3 peptídeos sintéticos derivados dessa glicoproteína de intestino [55]. A partir de análise da Bm86 e da avaliação de algu- mas propriedades da proteína, como potencial hidrofóbico e hidrofílico, foram definidos três possíveis determinantes imunogênicos com 14 a 15 aminoácidos. Bovinos foram imunizados com os peptídeos sintetizados e após infestados com 1.500 larvas de B. microplus. Anticorpos ( $\mathrm{IgG}$ ) gerados contra os peptídeos sintéticos atingiram títulos entre $400 \mathrm{e}$ 2.400, obtidos após 2 ou 3 imunizações e reconheceram a proteína Bm86 in situ, especialmente no interior dos vacúolos digestivos. Os resultados da infestação experimental demonstraram uma eficácia de $72.4 \%$, $81.05 \%$ e $35.87 \%$ nos bovinos imunizados com peptídeo A (SBm4912), B (SBm7462) e C (SBm19733), respectivamente [55].

O potencial imunogênico da vitelina, principal proteína de reserva do ovo, foi avaliado em experimentos de imunização, usando ovinos como modelo experimental [73]. A espécie ovina tem sido utilizada como modelo para identificação e avaliação de novos antígenos. No referido estudo, foram avaliadas duas glicoproteínas derivadas do complexo vitelina, uma de $87 \mathrm{kDa}$ (VIT87) e outra de $80 \mathrm{kDa}$ (GP80), purificadas a partir de ovos e larvas, respectivamente. VIT 87 e GP80 foram idênticas em no mínimo 11 resíduos de aminoácidos na extremidade aminoterminal, demonstrando serem altamente relacionadas, porém não idênticas [73]. Ovinos imunizados com VIT87 ou GP80 foram desafiados com 10 fêmeas e 10 machos de carrapatos adultos. A eficácia global da imunização, mensurada pela redução no número de larvas após um ciclo completo, foi de $68 \%$ com VIT87 e $66 \%$ com GP80. No mesmo estudo, os autores relataram a avaliação de uma GP80 expressa em E. coli. Entretanto, os resultados obtidos em ovinos imunizados com a proteína recombinante não apresentaram diferenças significativas em relação ao grupo controle. Esse resultado pode estar relacionado a ausência de glicosilação ou a estrutura terciária incorreta da proteína recombinante obtida em E. coli [73]. Tendo em vista que os antígenos estudados até o momento são glicoproteínas, a ausência de glicosilação das proteínas heterólogas obtidas em sistema procariota é um problema potencial no desenvolvimento vacinas recombinantes contra o $B$. microplus. Porém, essa dificuldade pode ser contornada pela utilização de um sistema de expressão eucarioto.

Outra metodologia utilizada é a produção de anticorpos monoclonais, que têm sido uma valiosa ferramenta na caracterização de antígenos envolvi- 
dos na resposta protetora contra parasitas [39]. Além de auxiliar no estudo da fisiologia do carrapato, a identificação e caracterização de proteínas alvo de monoclonais auxilia a identificação e avaliação do potencial vacinal de novos antígenos. Um anticorpo monoclonal (denominado $\mathrm{BrBm} 2$ ), produzido a partir de extrato de intestino de B. microplus, reduziu em até $70 \%$ a capacidade de ovoposição e aumentou a mortalidade de teleóginas inoculadas na hemocele [74]. Esses efeitos foram dependentes da concentração de anticorpos inoculada. Outros monoclonais (BrBm1, $\mathrm{BrBm} 3$ e BrBm4) foram produzidos a partir da imunização de camundongos com extrato de embrião. $\mathrm{O} \mathrm{BrBm} 1$ reage com antígenos presentes em diferentes tecidos e afetou a postura em aproximadamente $50 \%$, enquanto $\mathrm{BrBm} 3 \mathrm{e} \mathrm{BrBm} 4$ reconhecem a proteína vitelina e não afetaram a eficiência reprodutiva [74].

\section{Antígenos relacionados a funções biológicas definidas}

Além dos antígenos já avaliados imunologicamente, descritos anteriormente, várias moléculas envolvidas na fisiologia do carrapato e sua interação com o hospedeiro têm sido descritas por diversos grupos de pesquisa, o estudo dessas proteínas pode permitir a identificação de novos antígenos para vacinas.

Braz et al. [5], demonstraram que o $B$. microplus não sintetiza heme, obtendo da hemoglobina do hospedeiro o heme necessário para o seu desenvolvimento. Como conseqüência disso, o carrapato bovino desenvolveu, ao longo de sua evolução, mecanismos para obtenção e reciclagem de heme. A existência destes mecanismos foi comprovada pela purificação e caracterização de uma aspártico proteinase ligadora de heme [69]. Esta proteína, denominada THAP (Tick Heme-binding Aspartic Proteinase) foi o primeiro relato de uma proteinase capaz de ligar heme e ter sua atividade regulada por esta molécula. Aparentemente, o substrato natural dessa proteína é a vitelina, que no caso do carrapato, também é uma hemeproteína. A THAP apresenta um único sítio de ligação de heme, distinto do sítio catalítico, e que reconhece os resíduos de ácido propiônico laterais do anel porfirínico. A adição de heme ao meio de incubação inibe a hidrólise da vitelina pela THAP, demonstrando que a enzima é regulada pela disponibilidade de heme. Essa regulação é um provável mecanismo de controle do stress oxidativo gerado pela degradação de heme
[69]. Experimentos in vitro para mensurar a capacidade de ligação de heme a vitelina, demonstraram que cada molécula de vitelina é capaz de ligar até 31 moléculas de heme, reforçando a teoria de controle do stress oxidativo [45]. No mesmo estudo, os autores apresentaram evidências de que a vitelina é a principal reservatório de heme que, além de fornecer heme para o desenvolvimento embrionário durante sua degradação, liga-se a qualquer molécula de heme livre que exceda a quantidade necessária para o desenvolvimento embrionário [45].

Glutationa S-transferase (GSTs) é uma família multi-funcional de enzimas presentes em animais e vegetais. Suas funções incluem transporte intracelular, participação em processos digestivos, síntese de prostaglandinas e, principalmente, na detoxificação de substâncias tóxicas e na proteção ao stress oxidativo [44, 61]. Altos níveis de expressão de GST têm sido relacionados à resistência a inseticidas em vários organismos [61], além de estar associada a reações alérgicas mediadas por IgE [54]. Em B. microplus a GST foi isolada de larvas [30] e de glândula salivar [61]. Entretanto, ainda não foram demonstradas evidências correlacionando a expressão de GST a resistência frente aos acaricidas. Uma GST clonada a partir de uma biblioteca de cDNA de glândula salivar de partenógina foi usada para expressão de GST recombinante, que apresentou atividade enzimática contra o substrato CDNB. Ensaios de RT-PCR com tecidos de B. microplus, indicaram que os sítios de síntese de BmGST são glândulas salivares e intestino de partenógina e teleógina [61].

Uma cisteíno endopeptidase degradadora de vitelina (VTDCE) foi purificada e caracterizada a partir de ovos de B. microplus [68]. Essa enzima é naturalmente associada à vitelina, sendo ativada por acidificação. Essa atividade foi demonstrada em larvas não alimentadas, ovários e ovos de fêmeas ingurgitadas, sugerindo um importante papel na embriogênese do carrapato bovino [68]. Assim como a BYC, o envolvimento na embriogênese associado à capacidade imunogênica fazem dessa cisteíno endopeptidase um antígeno potencial, que poderia ser utilizado em associação com a BYC [68].

Anteriormente, uma cisteíno endopeptidase recombinante já havia sido obtida de uma biblioteca de cDNA de larva de carrapato [58]. A expressão do clone em E. coli permitiu a obtenção da proteína recombinante (BmCL1), que foi capaz de hidrolisar diferentes substratos sintéticos assim como, hemoglo- 
bina e vitelina, com atividade ótima em pH ácido. Análise por RT-PCR demonstrou que o gene é expresso no estágio larval do carrapato [58]. A proteína recombinante também foi utilizada para obtenção de anticorpo policlonal, que permitiu a localização desta proteína em larvas, partenóginas e teleóginas, através de western-blots. Em experimento de imunolocalização, a enzima foi detectada em células secretoras do intestino. Baseados nesses achados, os autores sugerem que a BmCL1 pode estar envolvida na degradação de hemoglobina no intestino de B. microplus [59].

Uma calreticulina (CRT), proteína que se liga a cálcio encontrada em um grande número de espécies e em todas as células nucleadas de mamíferos [50] foi identificada e caracterizada em B. microplus [23]. Suas possíveis funções incluem estocagem de cálcio, mediação da função de integrinas, ligação de C1q, lectina extracelular, chaperonina, além de inibir a expressão gênica regulada por esteróides [8]. A calreticulina humana é descrita como capaz de inibir a via clássica do sistema complemento pela sua ligação direta a C1q [42]. No carrapato Amblyomma americanum foi demonstrado a secreção de calreticulina pela saliva, sendo sugerido que atue modulando o sistema imune e/ou hemostase do hospedeiro [35]. Também foi citado que neste carrapato a calreticulina pode ser utilizada como biomarcador e que níveis de anticorpos contra esta proteína podem estar diretamente relacionados com índices de ingurgitação [64; 65]. A proteína recombinante (rBmCRT) foi utilizada na imunização de um bovino, porém ela não se mostrou imunogênica. Soro de bovinos naturalmente infestados também não reconheceram a rBmCRT [23]. Análises feitas por RT-PCR demonstraram que o seu mRNA é sintetizado em todos os tecidos e órgãos analisados [23]. A caracterização da presença da atividade anticomplementar na saliva do B. microplus poderá representar um significativo avanço na compreensão da importância da evasão do sistema complemento pelo carrapato, e na avaliação da possibilidade de inibindo a calreticulina, afetar sua viabilidade.

A paramiosina foi identificada e localizada em vários invertebrados, incluindo artrópodes, moluscos e nematódeos [47]. A função da paramiosina em músculo de invertebrados não é totalmente conhecida. Altos níveis de paramiosina em músculo de moluscos foram relacionados com o estado fisiológico conhecido como "catch mechanism". Esta condição permite longos períodos de tensão muscular com uma quantidade reduzida de energia. A paramiosina de Schistosoma japonicum tem sido testada como imunógeno em experimentos de vacinação. Experimentos de transferência passiva de anticorpos antiparamiosina demonstrando atividade protetora, têm estimulado a investigação da paramiosina como componente de uma vacina para esquistossomose [25]. Outra observação interessante é de que a paramiosina inibe ativação de complemento in vitro, sugerindo uma função de imunomodulação da resposta do hospedeiro [43]. O cDNA de uma paramiosina de B. microplus (BmPRM) foi isolado, caracterizado e expresso em E. coli, codificando uma proteína de $102 \mathrm{kDa}$ [22]. A sequência obtida mostrou alta similaridade à paramiosina de outros organismos. Anticorpos anti-BmPRM foram utilizados em Westernblots e demonstraram a presença de paramiosina em todos os tecidos e estágios de desenvolvimento do carrapato, mas não foi detectada na saliva. $\mathrm{A}$ rBmPRM ligou-se a IgG e ao colágeno. Essas características sugerem o envolvimento dessa proteína na modulação da resposta imunológica do hospedeiro [22].

Uma proteína inibidora de trombina, com massa molecular de $60 \mathrm{kDa}$, foi purificada da saliva de $B$. microplus e teve sua atividade anticoagulante demonstrada [33]. Os resultados obtidos, demonstraram que a saliva do carrapato é capaz de inibir tanto a via intrínsica como extrínsica da coagulação, inibindo a atividade amidolítica da trombina, um fator comum às duas vias. A identificação de anticoagulantes na saliva do carrapato confirma a existência de mecanismos específicos que permitem o hematofagismo e pode ser um alvo para o controle do parasitismo [33].

Após evidenciar a presença de atividade kininase em extrato de glândula salivar de B. microplus, Bastiani et al.[3] purificaram e caracterizaram essa enzima, que foi chamada de BooKase. Os ensaios de atividade demonstraram que a BooKase é uma metaloendopeptidase ativada por tiol capaz de hidrolisar bradicinina, um peptídeo biologicamente ativo importante no controle da pressão sanguínea e na resposta inflamatória. Porém, essa atividade cininase não foi observada na saliva de teleóginas parcialmente ingurgitadas. Baseado nisso, os autores sugerem que o papel fisiológico da BooKase pode estar associado a estágios iniciais do parasitismo, como na saliva de larvas recém fixadas [3]. 
Os estudos realizados até o momento justificam a confiança sobre a viabilidade do desenvolvimento de uma vacina e ou de controle biológico. Porém, uma vacina com reais possibilidades de substituir o uso de acaricidas ainda não está disponível. Por isto, até o momento em que os controles imunológico ou biológico sejam uma realidade totalmente prática, é importante o estudo dos mecanismos que permitem aos carrapatos desenvolverem resistência aos produtos químicos. Desta maneira poderemos compreender as bases moleculares da resistência, criar métodos e orientar práticas de manejo que permitam prolongar a vida útil dos princípios ativos em uso, além de desenvolver drogas menos sensíveis ao desenvolvimento de resistência pelos carrapatos.

\section{Base molecular da resistência aos acaricidas}

A base molecular da resistência tem sido estudada em diferentes espécies de artrópodes, principalmente em insetos. Mecanismos de resistência, como redução da penetração do inseticida, aumento do poder seqüestrante de compostos tóxicos e aumento da detoxificação tornam os inseticidas menos efetivos, fazendo com que seja necessário o aumento de dosificação. Três famílias de proteínas são as principais responsáveis pelo metabolismo de inseticidas: os citocromos $\mathrm{P} 450$, as carboxilesterases (COEs) e as glutationa S-transferases (GSTs) [57]. As proteínas destas famílias também estão envolvidas na síntese e na quebra de vários metabólitos endógenos, na proteção contra o stress oxidativo, na transmissão de sinais nervosos e no transporte celular [31].

A resistência a inseticidas pode resultar de mudanças na seqüência ou na conformação de proteínas que normalmente se ligariam a estes compostos [31]. A resistência a ciclodienos está relacionada a mutações de um receptor do neurotransmissor GABA, para organofosforados e carbamatos a mutações no sítio ativo da acetilcolinesterase e a amplificação do gene de esterases, para DDT e piretróides a mutações ligadas ao gene de um canal de sódio e ao citocromo P450. Mutações em genes de esterases em moscas domésticas também estão associadas a resistência a organofosforados [57]. As mesmas mutações que causam resistência a um mesmo princípio ativo são encontradas em diferentes espécies de insetos, indicando que o uso dos produtos químicos causa uma pressão ambiental que seleciona mutações nos diferentes genes [7].
Especificamente, para piretróides foram detectadas resistências por diminuição da sensibilidade aos produtos químicos e por aumento da capacidade de detoxificação celular. Alterações nos canais de sódio causam redução na sensibilidade do sistema nervoso central aos princípios ativos [48], e mutações que afetam a expressão dos genes dos citocromos P450, esterases e glutationa S-transferase são responsáveis pelo aumento da capacidade das células de eliminarem os princípios ativos [7].

Em B. microplus existem poucos estudos sobre a caracterização dos genes responsáveis pela resistência a diferentes princípios químicos. Existe correlação de enzimas da família das esterases com a resistência a piretróides [19]. No carrapato apenas os genes de esterase [10; 11], carboxilesterase [32], acetil-colinesterase [4], de citocromo P450 [13] e canal de sódio [30], que em outros organismos estão relacionados com a resistência a piretróides, foram parcialmente estudados para determinar a real participação de seus produtos na resistência aos princípios químicos. Ainda sim, diversos trabalhos mostram a resistência de populações $B$. microplus a diferentes pesticidas [20; 40]. A maior parte das populações de $B$. microplus no mundo são resistentes a organofosforados [11] e piretróides. Já foi identificada resistência a amitraz, um acaricida do grupo das formamidinas que age sobre receptores de octopamina, resultando em hiperexcitação neuronal e morte [72], em diversas populações de carrapato [51]. Novos acaricidas estão sendo testados no mercado, entre eles as lactonas macrocíclicas, que agem como bloqueadores da estimulação neural por se ligarem ao neurotransmissor GABA [72], o inibidor de desenvolvimento de carrapato flurazuron e fipronil. Como são relativamente novos no mercado, nenhum caso de resistência relevante ainda foi detectado [62].

Atualmente, a determinação da resistência em carrapatos é feita por testes biológicos a campo ou em laboratório. Os testes baseiam-se na utilização do carrapaticida em diferentes concentrações e na observação da eficiência do princípio ativo em diminuir a população de carrapatos. Guerrero et al. [27], através da técnica de PCR, conseguiram diagnosticar, em linhagens mexicanas de B. microplus, mutações por substituição de dois aminoácidos de uma proteína de canal de sódio. Essas mutações, substituições de Phe para Ile e Asp para Asn são responsáveis por conferir a estas linhagens de carrapato resistência a piretróides.

A identificação e caracterização dos genes de B. microplus que estão envolvidos na resistência a 
carrapaticidas, através da determinação do seu papel sobre a resistência e o estabelecimento de métodos que possam detectar sua presença em amostras de campo poderão fornecer uma importante ferramenta para o monitoramento da presença de resistência ao princípio ativo em populações de carrapatos a campo.

\section{Conclusão}

Concluindo, os problemas de resistência, o alto custo dos produtos químicos e da mão-de-obra na aplicação dos produtos, bem como o aparecimento de resíduos tóxicos na carne e no leite e a contaminação do ambiente, levaram à procura de métodos biológicos e imunológicos como formas alternativas de controle do carrapato, entretanto estes métodos ainda não satisfazem completamente as necessidades da pecuária, por isto uma alternativa em curto prazo é o melhor uso dos acaricidas. Além disso, uma melhor compreensão da biologia do carrapato é essencial para o desenvolvimento tanto, de novas drogas químicas como para vacinas e produtos biológicos.

\section{REFERÊNCIAS}

1 Alves-Branco F.P., Echevarria F.A.M. \& Siqueira A.S. 1983. Garça vaqueira Egretta ibis e o controle biológico do carrapato Boophilus microplus. Comunicado Técnico da EMBRAPA. 1: 1-4.

2 Andreotti R., Gomes A., Malavazi-Piza K.C., Sasaki S.D., Sampaio C.A. \& Tanaka A.S. 2002. BmTI antigens induce a bovine protective immune response against Boophilus microplus tick. International Immunopharmacology. 2: 557-563.

3 Bastiani M., Hillebrand S., Horn F., Kist T.B., Guimaraes J.A. \& Termignoni C. 2002. Cattle tick Boophilus microplus salivary gland contains a thiol-activated metalloendopeptidase displaying kininase activity. Insect Biochemical and Molecular Biology. 32: 1439-1446.

4 Baxter G. D. \& Barker, S. C. 2002. Analysis of the sequence and expression of a second putative acetylcholinesterase cDNA from organophosphate-susceptible and organophosphate-resistant cattle ticks. Insect Biochemical and Molecular Biology. 32: 815-820.

5 Braz G.R., Moreira M.F., Masuda H. \& Oliveira P.L. 2002. Rhodnius heme-binding protein (RHBP) is a heme source for embryonic development in the blood-sucking bug Rhodnius prolixus (Hemiptera, Reduviidae). Insect Biochemical and Molecular Biology. 32: 361-367.

6 Brum J.G.W. 1988. Infecção em teleóginas de Boophilus microplus (Acari: Ixodidae) por Cedecea lapagei Grimont et al., 1981: etiopatogenia e sazonalidade. 200p. Tese (Doutor em ciências). Instituto de Biologia. Universidade Federal Rural do Rio de Janeiro, R.J.

7 Casida J.E. \& Quistad G.B. 1998. Golden age of insecticide: Past, Present, or Future? Annual Review of Entomology. 43:1-16.

8 Coppolino M.G., \& Dedhar S. 1998. Molecules in focus: calreticulin. The International Journal of Biochemistry and Cell Biology. 30: 553-558.

9 Cordovés C.O. 1999. Carrapato: controle ou erradicação. Alegrete: Editora Gralha, 130 p.

10 Cossio-Bayugar R., Barhoumi R., Burghardt, R.C., Wagner G.G. \& Holman P.J. 2002. Basal cellular alterations of esterase, glutathione, glutathione S-transferase, intracellular calcium and membrane potenctials in coumaphos-resistant Boophilus microplus (Acari: Ixodidae) cell lines. Pesticide Biochemistry and Physiology. 72: 1-9.

11 Cossio-Bayugar R., Wagner G.G. \& Holman P.J. 2002. In vitro generation of organophosphate resistant Boophilus microplus (Acari: Ixodidae) cell lines. Journal of Medical Entomology. 39: 278-284.

12 Crampton A.L., Baxter G.D. \& Barker S.C. 1999. Identification and characterisation of a cytochrome P450 gene and processed pseudogene from an arachnid: the cattle tick, Boophilus microplus. Insect Biochemical and Molecular Biology. 29: 377-384.

13 Crampton A.L., Miller C., Baxter G.D. \& Barker S.C. 1998. Expressed sequenced tags and news genes from the cattle tick, Boophilus microplus. Experimental and Applied Acarology. 22: 177-186.

14 Da Costa GL, Sarquis M.I., De Moraes A.M. \& Bittencourt V.R. 2002. Isolation of Beauveria bassiana and Metarhizium anisopliae var. anisopliae from Boophilus microplus tick (Canestrini, 1887), in Rio de Janeiro State, Brazil. Mycopathologia. 154:207-209. 
15 Da Silva Vaz Jr I., Ozaki S.L. \& Masuda A. 1994. Serum of Boophilus microplus infested cattle reacts with different tick tissues. Veterinary Parasitology. 52: 71-78.

16 Da Silva Vaz Jr I., Martinez R.H.M., Oliveira A.T.D., Heck A., Logullo C., Gonzales J.C., Dewes H. \& Masuda A. 1996. Functional bovine immunoglobulins in Boophilus microplus hemolymph. Veterinary Parasitology. 62: 155-160.

17 Da Silva Vaz Jr. I., Logullo C. J., Sorgine M., Velloso F.F., Gonzales J.C., Masuda H., Oliveira P. L. \& Masuda A. 1998. Immunization of bovines with a new protein isolated from egg of Boophilus microplus. Veterinary Immunology and Immunopathology. 66: 331-341.

18 Davey R.B., George J.E. \& Snyder D.E. 2001. Efficacy of a single whole-body spray treatment of spinosad, against Boophilus microplus (Acari: Ixodidae) on cattle. Veterinary Parasitology. 99: 41-52.

19 Dejersey J., Nolan J., Dave P.A. \& Riccles P.W. 1985. Separation and characterization of the pyrethroid-hydrolyzing esterases of cattle tick Boophilus microplus. Pesticide and Biochemistry Physiology. 23: 349-357.

20 Drummond R.O., Ernst S.E., Trevino J.L., Gladney W.J. \& Graham O.H. 1976. Tests of acaricides for control of Boophilus annulatus and B. microplus. Journal of Economic Entomology. 69:37-40.

21 Farias N.A.R., Gonzales J.C. \& Saibro J.C. 1986. Antibiose e antixenose entre forrageiras em larvas de carrapato do boi. Pesquisa Agropecuária Brasileira. 21: 1313-1320.

22 Ferreira C.A., Barbosa M.C., Silveira T.C., Valenzuela J.G., da Silva Vaz Jr. I. \& Masuda A. 2002. cDNA cloning, expression and characterization of a Boophilus microplus paramyosin. Parasitology. 125: 265-274.

23 Ferreira C.A., da Silva Vaz Jr. I., da Silva S.S., Haag K.L., Valenzuela J.G. \& Masuda A. 2002. Cloning and partial characterization of a Boophilus microplus (Acari: Ixodidae) calreticulin. Experimental Parasitology. 101: 25-34.

24 Frazzon, A. P., da Silva Vaz Jr. I., Masuda, A., Schrank A. \& Vainstein, M. H. 2000. In vitro assessment of Metarhizium anisopliae isolates to control the cattle tick Boophilus microplus. Veterinary Parasitology. 94: 117-125.

25 Gobert G.N. 1998. The role of microscopy in the investigation of paramyosin as a vaccine candidate against Schistosoma japonicum. Parasitology Today. 14: 115-118.

26 Gonzales J.C. 1975. O controle do carrapato bovino. Porto Alegre: Sulina, 104 p.

27 Guerrero F.D., Li A.Y., Hernandez R. 2002. Molecular diagnosis of pyrethroid resistance in Mexican strains of Boophilus microplus (Acari: Ixodidae). Journal of Medical entomology. 39: 770-776.

28 Guglielmone A.A., Mangold A.J., Munoz Cobenas M.E., Scherling N., Garcia Posse F., Anziani O.S. \& Ioppolo M. 2000. Moxidectin pour-on for control of natural populations of the cattle tick Boophilus microplus (Acarina: Ixodidae). Veterinary Parasitology. 87: 237-241.

29 Häuserman W., Friedel T., Hess E.A. \& Strong M.B. 1992. A new active ingredient for a new approach to protect cattle against ticks In: Proceedings of XIX International Congress of Entomology (Beijing, China). p. 138.

30 He H., Chen A.C., Davey R.B., Ivie G.W. \& George, J.E. 1999. Characterization and molecular cloning of glutathione Stransferase gene from the tick, Boophilus microplus (Acari: Ixodidae). Insect and Biochemistry and Molecular Biology. 29: 737-743.

31 Hemingway J., Field L. \& Vontas J. 2002. An overview of insecticide resistance. Science. 298: 96-97.

32 Hernandez R., Guerrero F.D., George J.E. \& Wagner G.G. 2002. Allele frequency and gene expression of a putative carboxylesterase-encoding gene in a pyrethroid resistant strain of the tick Boophilus microplus. Insect Biochemistry and Molecular Biology. 32: 1009-1016.

33 Horn F., dos Santos P.C., Termignoni C. 2000. Boophilus microplus anticoagulant protein: an antithrombin inhibitor isolated from the cattle tick saliva. Archives of Biochemistry and Biophysics. 384: 68-73.

34 Horn S.C. \& Arteche C.C.P. 1985. Situação parasitária da pecuária no Brasil. A hora Veterinária. 23: 12-32.

35 Jaworski D. C., Simmen F. A., Lamoreaux W., Coons L. B., Muller M. T. \& Needham G. R. 1995. A secreted calreticulin protein in ixodid tick (Amblyomma americanum) saliva. Journal Insect Physiology. 41: 369-375.

36 Johnston L.A.Y., Kemp D.H. \& Pearson R.D. 1986. Immunization of cattle against Boophilus microplus using extracts derived from adult female ticks: Effects of induced immunity on tick populations. International Journal for Parasitology. 16: 27-34.

37 Jonsson N.N., Mayer D.G. \& Green P.E., 2000. Possible risk factors on Queensland dairy farms for acaricide resistance in cattle tick (Boophilus microplus). Veterinary Parasitology. 88: 79-92.

38 Kaaya G.P., Mwangi E.N. \& Ouna E.A. 1996. Prospects for biological control of livestock ticks, Rhipicephalus appendiculatus and Amblyomma variegatum, using the entomogenous fungi Beauveria bassiana and Metarhizium anisopliae. Journal of Invertebrate Pathology. 67: 15-20. 
39 Kelly, E.A.B., Colley, D.G. 1988. In vivo effects of monoclonal anti-13t4 antibody on immune responsiveness of mice infected with Schistosoma-mansoni - reduction of irradiated cercariae-induced resistance. Journal of Immunology. 140:2737-2745.

40 Sabatini G.A., Kemp D.H., Hughes S., Nari A. \& Hansen J. 2001. Tests to determine LC50 and discriminating doses for macrocyclic lactones against the cattle tick, Boophilus microplus. Veterinary Parasitology.95: 53-62

41 Kocan K.M. 1995. Targeting ticks for control of selected haemoparasitic diseases of cattle. Veterinary Parasitology. 57: $121-151$.

42 Kovacs H., Campbell I.D., Strong P., Johnson S., Ward F.J., Reid K.B.M. \& Eggleton, P. 1998. Evidence that C1q binds specifically to $\mathrm{C}_{\mathrm{H}}$ 2-like immunoglobulin $\mathrm{g}$ motifs present in the autoantigen calreticulin and interferes with complement activation. Biochemistry. 37: 17865-17874.

43 Laclette J.P., Shoemaker C.B., Richter D., Arcos L., Pante N., Cohen C., Bing D. \& Nicholson-Weller A. 1992. Paramyosin inhibits complement C1. The Journal of Immunology. 148: 124-128.

44 Lee A.J., Huntley J., Van den Broek A., Coates D. \& Isaac R.E. 2002. Expression and characterisation of a Psoroptes ovis glutathione S-transferase. Veterinary Parasitology. 105: 49-63.

45 Logullo C., Moraes J., Dansa-Petretski M., Da Silva Vaz Jr. I., Masuda A., Sorgine M.H., Braz G.R., Masuda, H. \& Oliveira, P.L. 2002. Binding and storage of heme by vitellin from the cattle tick, Boophilus microplus. Insect Biochemistry and Molecular Biology. 32: 1805-1811.

46 Logullo C., Da Silva Vaz Jr. I., Sorgine M.H.F., Paiva-Silva G.O., Faria F.S., Zingali R., Rosa de Lima M., Abreu L., Oliveira E.F., Alves E.W., Masuda H., Gonzales J.C., Masuda A. \& Oliveira P.L. 1998. Isolation of an aspartic proteinase precursor from the egg of a hard tick, Boophilus microplus. Parasitology. 116: 525-532.

47 Maroto, M., Arredondo, J.J., San Roman, M., Marco, R. \& Cervera, M. 1995. Analysis of the paramyosin/miniparamyosin gene. The Journal of Biological Chemistry 270: 4375-4382.

48 Martinez-Torres D., Chandre F., Williamson M.S., Darriet F., Bergé J.B., Devonshire A.L., Guillet P., Pasteur N. \& Pauron, D. 1998. Molecular characterization of pyrethroid knockdown resistance $(k d r)$ in the major malaria vector Anopheles gambiae s.s. Insect Molecular Biology. 7: 189-184.

49 Gonçalves P.M., Passos L. M. F \& Ribeiro M. F. B. 1999. Detection of IgM antibodies against Babesia bovis in cattle. Veterinary Parasitology. 82: 11-17.

50 Michalak, M., Milner, R.E., Burns, K., Opas, M. 1992. Calreticulin. Biochemical Journal. 285, 681-692.

51 Miller, R.J., Davey, R.B., George, J.E. 2002. Modification of the food and agriculture organization larval packet test to measure amitraz-susceptibility against ixodidae. Journal of Medical Entomology. 39: 645-651.

52 Nari A. 1995. Strategies for the control of one-host ticks and relationship with tick-borne diseases in South America. Veterinary Parasitology. 57: 153-165.

53 Nolan J. 1985. Mechanisms of resistance to chemicals in arthropod parasites of veterinary importance. Veterinary Parasitology. 18: 155-166.

54 O’Neill G.M., Donovan G.R. \& Baldo B.A. 1994. Cloning and characterization of a major allergen of the house dust mite, Dermatophagoides pteronyssinus, homologous with glutathione S-transferase. Biochimica et Biophysica Acta. 1219: $521-528$.

55 Patarroyo J.H., Portela R.W., De Castro R.O., Pimentel J.C., Guzman F., Patarroyo M.E., Vargas M.I., Prates A.A. \& Mendes M.A. 2002. Immunization of cattle with synthetic peptides derived from the Boophilus microplus gut protein (Bm86). Veterinary Immunology and Immunopathology. 88: 163-172.

56 Pruett J.H. 1999. Immunological control of arthropods ectoparasites - a review. International Journal for Parasitology 29: 25-32.

57 Ranson H., Claudianos C., Ortelli F., Abgrall C., Hemingway J., Sharakhova M.V., Unger M.F., Collins F.H. \& Feyereisen R. 2002. Evolution of supergene families associated with insecticide resistance. Science. 298: 179-181.

58 Renard G., Garcia J.F., Cardoso F.C., Richter M.F., Sakanari J.A., Ozaki L.S., Termignoni C. \& Masuda, A. 2000. Cloning and functional expression of a Boophilus microplus cathepsin L-like enzyme. Insect Biochemistry and Molecular Biology. 30: 1017-1026.

59 Renard G., Lara F.A., de Cardoso F.C., Miguens F.C., Dansa-Petretski M., Termignoni C. \& Masuda A. 2002. Expression and immunolocalization of a Boophilus microplus cathepsin L-like enzyme. Insect Molecular Biology. 11: 325-328.

60 Riding G.A., Jarmey J., Makenna R.V., Pearson R., Cobon G.S. \& Willadsen P. 1994. A protective “concealed" antigen from Boophilus microplus. Purification, localization, and possible function. Journal of Immunology. 153: 5158-5166. 
61 Rosa de Lima M.F., Sanchez Ferreira C.A., Joaquim de Freitas D.R., Valenzuela J.G. \& Masuda, A. 2002. Cloning and partial characterization of a Boophilus microplus (Acari: Ixodidae) glutathione S-transferase. Insect Biochemistry and Molecular Biology. 32: 747-754.

62 Sabatini G.A., Kemp D.H., Hughes S., Nari A. \& Hansen J. 2001. Tests to determine LC50 and discriminating doses for macrocyclic lactones against the cattle tick, Boophilus microplus. Veterinary Parasitology. 95: 53-62.

63 Samish M. \& Glazer, I. 2001. Entomopathogenic nematodes for the biocontrol of ticks. Trends in Parasitology. 17: 368371.

64 Sanders M.L., Glass G.E., Nadelman R.B., Wormser G.P., Scott A.L., Raha S., Ritchie B.C., Jaworski D.C. \& Schwartz B.S. 1999. Antibody levels to recombinant tick calreticulin increase in humans after exposure to Ixodes scapularis (Say) and are correlated with tick engorgement indices. Americam Journal of Epidemiology. 149, 777-784.

65 Sanders M.L., Jaworski D.C., Sanchez J.L., DeFraites R.F., Glass G.E., Scott A.L., Raha S., Ritchie B.C., Needham G.R. \& Schwartz, B. S. 1998. Antibody to a cDNA-derived calreticulin protein from Amblyomma americanum as a biomarker of tick exposure in humans. American Journal of Tropical Medicine and Hygiene. 59: 279-285.

66 Seddon H.R. 1967. In: Diseases of Domestic Animals in Australia, Part 3, Arthropod Infestations, Ticks and Mites. Ed. and revised: H.E. Albiston, Commonwealth of Australia, Dept. Health, Canberra. p.40.

67 Seifert G.W., Springell P.H. \& Tatchell R.J. 1968. Radioactive studies on the feeding of larvae, nymphs and adults of the cattle tick Boophilus microplus (Canestrini). Parasitology. 58: 415-430.

68 Seixas A., Dos Santos P.C., Velloso F.F., Da Silva Vaz Jr. I., Masuda A., Horn F. \& Termignoni C. 2003. A Boophilus microplus vitellin-degrading cysteine endopeptidase. Parasitology. 126: 155-163.

69 Sorgine M.H., Logullo C., Zingali R.B., Paiva-Silva G.O., Juliano L. \& Oliveira P.L. 2000. A heme-binding aspartic proteinase from the eggs of the hard tick Boophilus microplus. Journal of Biological Chemistry. 275: 28659-28665.

70 Sutherst R.W., Jones R.J., Schnitzerling H.J. 1982. Tropical legumes of the genus Stylosanthes immobilize and kill cattle ticks. Nature. 295: 320-321.

71 Sutherst R.W., Maywald G.F., Kerr J.D. \& Siegeman D.A. 1983. The effect of the cattle tick (Boophilus microplus) on the growth of Bos indicus x Bos taurus steers. Australian Journal of Agricultural Research. 34: 317-327.

72 Taylor M.A. 2001. Recent developments in ectoparasiticides. The Veterinay Journal. 161: 253-268.

73 Tellam R.L., Kemp D., Riding G., Briscoe S., Smith D., Sharp P., Irving D. \& Willadsen, P. 2002. Reduced oviposition of Boophilus microplus feeding on sheep vaccinated with vitellin. Veterinary Parasitology. 103: 141-156.

74 Toro-Ortiz R.D., Da Silva Vaz Jr., I., Gonzales J.C. \& Masuda, A. 1997. Monoclonal antibodies against Boophilus microplus and their effects on tick reproductive efficiency. Veterinary Parasitology. 69: 297-306

75 Trimnell A.R., Hails R.S. \& Nuttall P.A. 2002. Dual action ectoparasite vaccine targeting 'exposed' and 'concealed' antigens. Vaccin.e 20: 3560-3568.

76 Wikel S.K. 1996.Tick Modulation of Host Cytokines. Experimental Parasitology. 84: 304-309

77 Willadsen P., Cobon G. \& McKenna R.V. 1996. Comparative vaccination of cattle against Boophilus microplus with recombinant antigen Bm86 or in combination with recombinant Bm91. Parasite Immunology. 18: 241-246.

78 Young A.S. \& Morzaria S.P. 1986. Biology of Babesia. Parasitology Today. 2: 211-219.

79 Zhioua E., Browning M., Johnson P.W., Ginsberg H.S. \& Lebrun R.A. 1997. Pathogenicity of the entomopathogenic fungus Metarhizium anisopliae (Deuteromycettes) to Ixodes scapularis (Acari: Ixodidae). Journal for Parasitology. 83: 815-818. 